\title{
A note on Fukui's note
}

\section{Cheng-Yu Edwin Tsai}

Harvard University

\begin{abstract}
This commentary relates Fukui's (2015) note on weak vs. strong generation to two aspects of quantification in Chinese: quantifier scope and the syntactic licensing conditions of noninterrogative $w h$-expressions. It is shown that the phenomena under discussion echo Fukui's (2015) view that only strong generation allows for a deeper understanding of natural language and that dependencies are to be distinguished structurally.
\end{abstract}

\section{Keywords}

strong generation, dependency, Chinese quantification, noninterrogative $w h$-phrases

Studies in Chinese Linguistics, Volume 36, Number 2, 2015, 69-80 DOI: 10.1515/scl-2015-0005 (C)2015 by T.T. Ng Chinese Language Research Centre, Institute of Chinese Studies, The Chinese University of Hong Kong 
In his note on "weak vs. strong generation," Naoki Fukui (2015) proposes the hypothesis in (1):

(1) Dependencies are possible in human language only when they are Mergegenerable.

With "dependency" understood as semantic/thematic association between two syntactic objects, this means the way Merge generates structures determines how the structures can be interpreted. He raises the following configurations as examples.

(2) $\mathrm{NP}_{1}-g a \mathrm{NP}_{2}-g a \mathrm{NP}_{3}-g a \ldots \mathrm{NP}_{n}-g a \ldots \mathrm{V}_{n}$-to $\ldots \mathrm{V}_{3}$-to $\mathrm{V}_{2}$-to $\mathrm{V}_{1}(-g a=\mathrm{Nom}$, to $=$ "that")

$$
\begin{aligned}
& \mathrm{NP}_{1} \text {-to } \mathrm{NP}_{2} \text {-to } \mathrm{NP}_{3} \text {-to } \ldots \mathrm{NP}_{n} \text {-(to-)ga, (sorezore "respectively") } \mathrm{V}_{1}, \mathrm{~V}_{2}, \mathrm{~V}_{3} \text {, } \\
& \ldots, \mathrm{V}_{n} \text { (to = "and") }
\end{aligned}
$$

While the strings in (2) and (3) both contain a sequence of NPs followed by another sequence of Vs, they are quite distinct in meaning. In particular, (2) only permits an interpretation like "John said that Bill thought that Mary laughed," whereas (3), a coordinate construction, may have the "group" reading such as "John, Bill and Mary collectively laughed, thought and said," or the cross-serial reading "John laughed, Mary thought and Bill said." Fukui (2015) suggests that this difference is correlated with the fact that (2) has a nested dependency in which neither the NPs nor the Vs form a constituent, thus disallowing any "group" or distributivelike cross-serial reading by virtue of (1). On the other hand, the sequence of NPs is a constituent in (3) and so is the sequence of Vs; through a properly defined "copying" relation and the assumption that Merge-generated structures are maximally preserved in linearization, group and cross-serial readings of (3) may also follow from (1). Crucially, cross-serial dependencies are possible only when relevant items (namely the NPs or Vs in (3)) form a constituent.

Fukui's (2015) observation exemplifies another theme of his note, namely the inadequacy of a theory the coverage of which is limited to the weak generative capacity (Chomsky 1965), which refers to the class of languages weakly generated by a grammar; weak generation produces a set of sentences basically. Weak generative capacity stands in opposition to strong generative capacity wherein a grammar generates a set of structural descriptions, and a theory is descriptively adequate if "its strong generative capacity includes the system of structural descriptions for each natural language" (ibid. p. 60). Fukui (2015) observes that the distinction of (2) and (3) would be difficult to make if one only looks at the terminal strings, namely the output of the weak generative capacity.

It is not hard to see that the permissible interpretation of a string of words is contingent on the structure generated by Merge. In (3), since the sequence of NPs constitutes a constituent, every NP in this constituent can occur in the domain of a (possibly syntactically realistic) operator $O p$ that gives rise to either the "group" or the distributive-like reading at some level of interpretation. $O p$ will, however, not 
be able to function in the same way in (2), if we assume that the relevant semantic effects it brings about are phase-bound (or clause-bound). And indeed, various quantificational phenomena have been argued to be local, for example, quantifier raising (May 1977) and the domain of the "strengthening" effect of any (Kadmon and Landman 1993).

In the field of Chinese generative grammar, one of the earliest qualifications of the distinction between weak vs. strong generative capacity has been prominently made by Huang (1982) on the scope relations of quantificational expressions. Huang observes that a linear condition, which dictates, for instance, "if a logical expression A precedes another logical expression B, then A also precedes (or takes scope over) B at LF" (cf. S.-F. Huang 1981), will be unable to account for cases like (4) and (5) where the first quantificational expression precedes, but does not scope over, the second.

(4) [Mai-le henduo shu de neige ren] dui meige ren dou hen keqi. buy-Aspmany book de that man to every man Dou very polite "The man who bought many books was polite to everybody."

\begin{tabular}{|c|c|c|c|}
\hline $\begin{array}{l}\text { Zhangsan } \\
\text { Zhangsan }\end{array}$ & $\begin{array}{l}\text { hen } \\
\text { very }\end{array}$ & $\begin{array}{l}\text { bu-gaoxing } \\
\text { not-happy }\end{array}$ & $\frac{\text { san-jian shiqing. }}{\text { three-Cl matter }}$ \\
\hline
\end{tabular}

(Huang 1982: 140)

"Zhangsan is very unhappy about three things."

(Huang 1982: 142)

On the other hand, a hierarchical condition based on c-command is not contradicted by such data, and furthermore can provide an account for the scope interpretation when couched with appropriate operations such as QR. In more formal terms, the quantified phrase (QP) "many books" in (4) is not Merged directly to the main clause, thus unable to scope above the QP "everybody." Likewise, the negation in (5) is considered left-adjacent to the main predicate at the $\mathrm{V}^{0}$-level, which does not Merge directly to VP, either, and thus does not bear scope above "three things." Instead, to interpret these sentences one will have to resort to QR, by which "everybody" in (4) and "three things" in (5) each adjoins to the IP that contains the other QP. The consideration of the abstract structural relations, that is, those by strong generation, is not only advantageous but also necessary once the empirical phenomenon requires an explanation beyond the study of weak generation.

Notice that QR typically does not feed the phonological component and should not be part of Narrow Syntax (Chomsky 2004). While the LF of (4), which is given in (6), may be conceived of as involving a nested dependency where the chain of the many-QP is nested under that of the every-QP, such dependency is invisible from the surface string of (4). In addition, there seems to be no nested dependency at all in (5) since negation does not move.

$$
\text { every ... }\left[_{\text {IP }}\left[_{\text {subject }} \ldots \text { many ... (many) ... }\right] \ldots \text { (every) ... }\right]
$$


What (4) (as well as (5)) demonstrates in the current context is therefore not that scope interpretation rests on a certain type of formal dependency, but that there are phenomena which cannot be well accommodated if one only looks at the dependencies defined on linear strings, that is, Fukui's (2015) second point in his introductory paragraphs. Whether LF structures expressing scope relations fall under the realm of strong generative capacity in Chomsky's (1965) conception is an open question. I thank a reviewer for his/her detailed comments that urged me to correct and clarify the argument I made regarding (4) and (5) in the previous draft.

The same reviewer further points out that the absence of scope ambiguity in examples like $(4) /(5)$ indicates rather that $\mathrm{QR}$ can be obviated from the core computation of the language faculty (Chomsky 2004). For one thing, corresponding quantified sentences of someone loves everyone and alike in Chinese as well as in Japanese do not show scope ambiguity, as is widely acknowledged in the literature (e.g. Hoji 1985, Aoun and Li 1993). For another, if the QP "many books" in (4) is substituted by an existential QP such as "one book" and the head noun by a bare NP, as in (7), the sentence does actually not display the reading according to which "everyone" scopes over "one book," contrary to the claim that the former undergoes QR to take wide scope.

(7) [Mai-le yi-ben shu de ren] dui meige ren dou hen keqi. buy-Asp one-Cl book DE man to every man DOU very polite "The man/men who bought one book was/were polite to everybody."

(*every > one, one > every)

The same observation is made by the other reviewer, who ascribes this fact to the exceptional wide-scope property of existentials (Fodor \& Sag 1982, Abusch 1994, among others).

While I agree that (7) does not have the [every $>$ one] scope reading, I believe it would not be accurate to say that Chinese lacks QR entirely. Consider (8): ${ }^{1}$

Mei-zhang zhuozi-shang de shu dou shi lanse-de.
every-Cl table-top DE book DOU be blue-DE
"The book(s) on every table is/are blue."

The significance of (8) is that mei "every" is structurally internal to the subject chunk, and yet this sentence conveys that "for every table, the book(s) on the table is/are blue." This is the reading where "every table" scopes above the indefinite bare noun "book" (which is neutral with respect to number). If QR of "every" does not occur, (8) should only have the pragmatically odd reading: "the books that are (simultaneously) on every table are blue." This reading is actually possible, but the point is that the firstly mentioned reading is, too, which is unexpected if

1 See Huang (1982: Section 4.1) for more examples and discussions on QR in Chinese. 
"every" stays in situ at LF. This observation is further strengthened by the fact that the classifier to which mei "every" is attached, zhang, is one that "matches" the locative NP zhuozi "table" rather than the head noun of the entire subject, that is, shu "book." (8) therefore makes a case where an available scope reading is obtained only when QR takes place. And if $\mathrm{QR}$ is a permissible operation in Chinese (no matter how marked it may be), there is always the possibility that QR contributes (at least partially) to the meaning of (4).

But that (7) lacks the [every > one] reading becomes mysterious. One may attribute it to the numeral phrase (NumP) "one book" being a "wide-scope" indefinite, as a reviewer suggests (see also Jiang 2012). This view implies that, like English $a$-indefinites, there should be "narrow-scope" construal of the same NumP as well, where such NumP takes scope below another quantificational element. It is not quite clear if this is borne out, however. The following examples are awkward at best: ${ }^{2}$

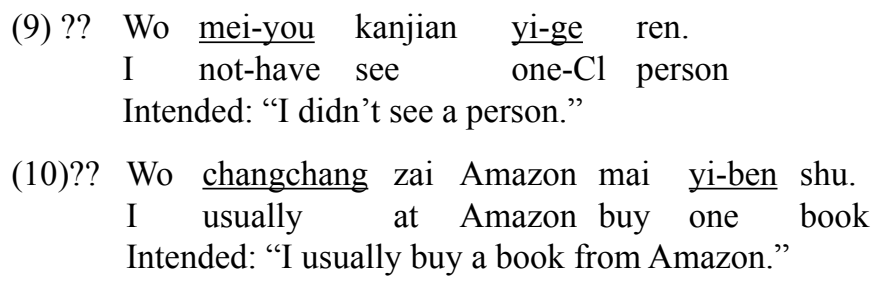

The intended reading of (9) is "I didn't see anyone," and that of (10) is one where the reference of "one book" depends on the adverb of quantification "usually." The peculiarity of these examples is that they sound quite unnatural in the first place, and not just that they fail to deliver the intended "narrow-scope" reading (or the "wide-scope" reading, for that matter). Scope interaction being one standard testing ground for the scope properties of a QP, the fact that such test falls short indicates Chinese NumPs may require a different treatment than that for typical indefinites in English. The "wide-scope" reading of the NumP in (7), in turn, should be derived via a different source than what has been proposed for widescope indefinites (e.g. choice functions, Reinhart 1997). ${ }^{3}$

There has been little study that systematically investigates the distribution of NumPs in Chinese and their interaction with other quantifiers. As it is not my intention to explore quantification in Chinese here, I shall make no further comment. It is nevertheless important to keep in mind that quantified sentences

\footnotetext{
That Chinese NumPs sound odd in the scope of negation is noted by S.-F. Huang (1981).

3 On the other hand, (9) does allow a marked interpretation, where the speaker intends to deny the positive counterpart of (9). Such "direct denial" construal however is largely context-dependent (i.e., there must be a positive counterpart in the preceding discourse to be denied). If a NumP is only felicitous on this particular use when under negation, it is reasonable to consider it not a typical indefinite (which has rather flexible scope properties independent of the context).
} 
such as (4) and (5) still make good cases for Fukui's (2015) point, regardless of whether Chinese observes QR or not, that solutions to many problems lie in the hierarchical (as opposed to linear) structures of human language.

Another domain that may be relevant to Fukui's (2015) note is the noninterrogative $w h$-construal in Chinese. It is known that wh-expressions in Chinese resemble those in Japanese in their "indeterminate" characteristics in the sense of Kuroda (1965) (Huang 1982, Cheng 1991, Li 1992, Tsai 1994, inter alia). (11) shows that when the in situ wh-word shei "who" occurs in a nonembedded nonmodalized context, it can only be interpreted as an interrogative pronoun. When the wh-clause in (11) precedes another clause that contains the quantificational particle dou as in (12), shei is turned into a universally quantified expression similar to whoever in English.
Lisi kanjian-le shei?
Lisi see-Asp who
"Who did Lisi see?"
(12) Lisi kanjian-le shei, Wangwu dou zhidao.
Lisi see-Asp who Wangwu DOU know
"Whoever Lisi saw, Wangwu knows it."

Roughly, what (12) means is that Wangwu knows all possible situations in which Lisi saw someone; this is an interpretation where dou scopes over the first clause, despite the word order. Since the interrogative reading is no longer available, it seems that dou either blocks the association between shei and the invisible question operator at $\mathrm{CP}$, or simply "replaces" the question operator. However, if the wh-clause in (12) is embedded under a matrix verb like believe, the scope of dou will be restricted to the embedded clause. Thus the sentence in (13) only has the (a)-reading and lacks the (b)-reading.

(13) Zhangsan xiangxin Lisi kanjian-le shei, Wangwu dou zhidao. Zhangsan believe Lisi see-Asp who Wangwu DOU know

a. "Zhangsan believes that whoever Lisi saw, Wangwu knows it." (Scope: "believe" > dou $>$ wh)

b. *'Whoever Zhangsan believes that Lisi saw, Wangwu knows it." (Scope: dou > "believe" > wh)

The interpretations of (12), (13a) and (13b) can be schematically given in (14), respectively, where coindexation is intended to mark the associated domain of dou.

(14) a. ${ }^{\sqrt{ }}\left[{ }_{\mathrm{CP}} \ldots w h \ldots\right]_{\mathrm{i}}\left[{ }_{\mathrm{CP}} \ldots d o u_{\mathrm{i}} \ldots\right]$

b. ${ }^{\sqrt{C P}} \ldots \mathrm{V}\left[\left[_{\mathrm{CP}}\left[\mathrm{CP}_{\mathrm{CP}} \ldots w h \ldots\right]_{\mathrm{i}}\left[\left[_{\mathrm{CP}} \ldots d o u_{\mathrm{i}} \ldots\right]\right]\right]\right.$

c. $*\left[_{\mathrm{CP}} \ldots \mathrm{V}\left[\left[_{\mathrm{CP}} \ldots w h \ldots\right]\right]_{\mathrm{i}}\left[\mathrm{CP}_{\mathrm{CP}} \ldots d o u_{\mathrm{i}} \ldots\right]\right.$ 
The status of $d o u$ is a quite intricate matter and I will not take a stand here. ${ }^{4}$ The point is that locality plays a critical role in the association or dependency between a $w h$-phrase/clause and a licensing operator, which is reminiscent of the contrast of (2) and (3) where the type of dependency goes hand in hand with the constituent structure. What (13) shows us is that in Chinese a wh-phrase must stay as "local" to dou as possible in order to establish a possible dependency with it, where locality may be defined on the basis of CP-phase along the lines of Chomsky (2000 et seq.). In short, the wh-clause must be Merged directly to the CP that hosts $d o u .^{5}$

One reviewer wonders why the reading of (13b) is not available, given the possibility of successive movement of a mediating operator between dou and "who" along the lines of (15) (cf. Watanabe 1992 on Japanese wh-constructions):
$\mathrm{OP}_{1,2}$ [Zhangsan xiangxin
[(OP) Lisi kanjian-le
(OP) shei $\left.\left._{1}\right]\right]$, Wangwu dou $_{2}$ zhidao

Note that (15) is not necessarily the only possible analysis. On Tsai's (1994) view, for instance, the particle dou acts as the universal quantifier that binds the variables provided by the wh-phrases in the antecedent clause, and dou occurs at some CP/ IP level (although how it can wind up binding the $w h$-phrases through c-command is unclear). In this treatment, the unavailability of the reading (13b) is due to the impossibility of dou appearing in (or taking effect from) the highest CP/IP of the antecedent clause. Several options are open as to why this should be the case, for example, dou cannot access $w h$-variables in a different phase.

The other reviewer observes that the reading of (13b) becomes available when the concessive conditional marker wulun 'no matter' is added to the whclause, as in (16). This is somewhat surprising if wulun 'no matter' is syntactically present in such dou-construction regardless of its phonetic form (Lin 1996).

(16) Wulun Zhangsan xiangxin Lisi kanjian-le shei, Wangwu dou zhidao. no.matter Zhangsan believe Lisi see-Asp who Wangwu Dou know "Whoever Zhangsan believes that Lisi saw, Wangwu knows it."

We may reasonably take wulun 'no matter' to be existent in the dou-construction under discussion, following Lin (1996), but at the same time stipulate that there is a tendency for it to be as close to the $w h$-variable(s) in its syntactic domain as possible. Assuming wulun 'no matter' appears in Comp, if it is not spelled out in $\mathrm{PF}$, as in (13), the default location of its covert counterpart is the lowest $\mathrm{CP}$ that dominates all relevant $w h$-variables (which renders (13) unambiguous); but

4 See Tsai (1994), Cheng (1995), Cheng and Huang (1996), Lin (1996), and Giannakidou and Cheng (2006) for different views on the relation between dou and wh-phrases.

5 Of course, Merge cannot be the only factor in determining the meaning and distribution of noninterrogative wh's. As Fukui (2015) has mentioned, even in narrow syntax, dependencies should come out as the interplay of Merge and other relations such as agreement and predication. Quantification of Chinese wh-phrases may likely fall within the same range of phenomena. 
if wulun 'no matter' surfaces in syntax, this restriction is relaxed and it can act like an explicit "scope marker" for dou in the main clause. Whether this analysis is plausible or not requires further investigation, though that (13) is unambiguous seems to be a solid fact.

There is another environment where a Chinese $w h$-phrase can be interpreted with universal force, namely "bare conditionals" as exemplified by (17).

(17) $\mathrm{Ni}$ chi shenme, wo jiu chi shenme.

you eat what I JIU eat what

"I will eat what(ever) you eat."

Cheng and Huang (1996) demonstrate that in this special type of conditional construction, the $w h$-items in the antecedent and in the consequent are bound by a sentential necessity operator and must match both in form and in reference, even though neither of them is inherently anaphoric. The relevance of bare conditionals to the current discussion is the cross-serial dependency of the wh-phrases involved. In the more complicated case (18), the subject $w h$ in the consequent is interpreted as referring to the same individual as the subject $w h$ in the antecedent, where coreference is indicated by coindexation. The same holds for the object $w h$ 's across the two clauses. ${ }^{6}$

$\underline{\text { Shei }}_{1}$ yan $\underline{\text { shei }}_{2}, \underline{\text { shei }}_{1}$ jiu xiang $\underline{\text { shei }}_{2}$. who play who who JIU resemble who "If X plays the role of Y, then X will resemble Y." (Cheng and Huang 1996: 129)

$$
O p_{1,2}\left[{ }_{\text {antecedent-CP }} \ldots w h_{1} \ldots w h_{2} \ldots\right]\left[_{\text {consequent-CP }} \ldots w h_{1} \ldots w h_{2} \ldots\right]
$$

There is more than one way to explicate the peculiar properties of the wh-items in bare conditionals. ${ }^{7}$ Nevertheless, it suffices for present purposes to note that the kind of interpretation in $(17) /(18)$ is at least partially conditioned by the hierarchical structure: it is only possible when neither of two coreferential $w h$-items c-commands the other. Moreover, unlike nested (i.e. embedded) dependencies that follow straightforwardly from Merge, cross-serial dependencies are relatively limited, as Fukui points out. Perhaps not incidentally, bare conditionals of the kind just discussed have also not been widely attested (but see Bruening 2007); such construction does not find a close counterpart even in Japanese, a language

6 In other cases, the first $w h$ in the antecedent may be coreferential with the second $w h$ in the consequent clause of a bare conditional, rendering a nested dependency (e.g. Shei $i_{1}$ ifu shei, shei $_{2}$ jiu baofu shei. . 'If X bullies Y, Y will avenge X.'). I thank a reviewer for pointing this out.

7 See, e.g., Chierchia (2000), Cheung (2006), Y. Huang (2010), and Luo and Crain (2011). 
with a similar system of indeterminate pronouns. ${ }^{8}$ By contrast, noninterrogative wh-expressions in other dependencies are much more broadly observed crosslinguistically. In fact, to the best of my knowledge, Chinese noninterrogative wh-phrases bear cross-serial dependency with their licensor only in the two environments in (12) and (18); they are always embedded in the scope of a licensor in other licensing contexts (Li 1992, Lin 1996).

Lastly, as Fukui (2015) and a reviewer have both noted, Merge alone is insufficient in generating a linearized string in a Merge-based syntactic theory. On the assumption that Merge is symmetric (Chomsky 2004) with respect to two given syntactic objects, it does not yield the distinction of nesting vs. self-embedding structures, nor does it determine how nested and cross-serial dependencies are formed differently. Unfortunately I am unable to address this empirical question of how linearization should kick in, though I would like to repeat one of Fukui's main themes, namely that nested and cross-serial dependencies are to be distinguished in structural terms: a cross-serial dependency is possible only when relevant terminal elements form a constituent, but a nested dependency is obtained by the application of Merge phrase-by-phase where each dependency is established in a different phase. If Chinese bare conditionals like (18) can indeed exemplify cross-serial dependency, we obtain a crucial distinction between the two types of dependencies, because in (18) the first two instances of shei "who" are not only subparts of a constituent but also within the same $(\mathrm{CP})$ phase.

To sum up, this short commentary addresses Fukui's (2015) note on weak vs. strong generation and the hypothesis in (1) from the perspective of Chinese. While Fukui (2015) does not address his examples and hypothesis from the view of quantification, it seems clear that related facts are also encompassed in the full generality of his proposal.

8 One reviewer notes that although Japanese does not have direct analogues of bare conditionals, it does have similar kinds of concessive conditionals when the $w h$-element in the consequent clause is suffixed with -mo which turns it into an NPI, as in (ia), or with -demo which renders it a freechoice-like item, as in (ib). These examples are compared with (ic), which disallows the empty object position to be filled by dare-ni 'who-DAT' without -mo or -demo.

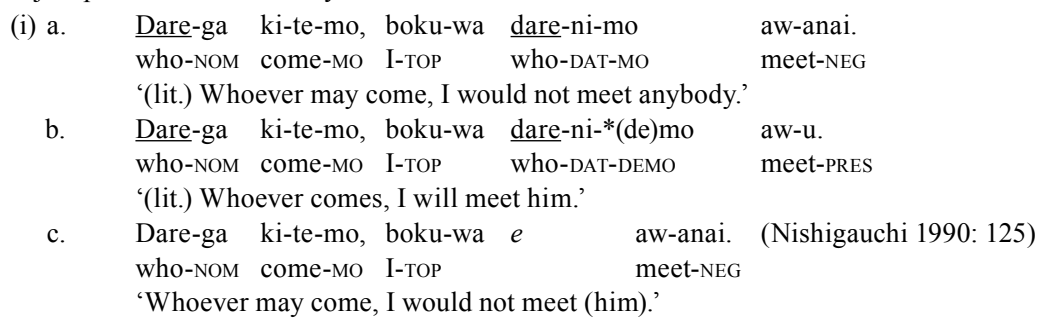

It remains to be seen whether Japanese also permits the same type of cross-serial dependency as in (18) with the company of -mo or -demo in the consequent clause. 


\section{Acknowledgments}

I am grateful to the two anonymous reviewers for their detailed comments and questions. I would also like to thank the Chief Editor Prof. SzeWing Tang for inviting me to submit this commentary. The responsibility for any error and misunderstanding remains my own.

\section{References}

Abusch, Dorit. 1994. The scope of indefinites. Natural Language Semantics 2. 83-135. Aoun, Joseph \& Y.-H. Audrey Li. 1993. Syntax of scope. Cambridge, MA: MIT Press. Bruening, Benjamin. 2007. Wh-in-situ does not correlate with wh-indefinites or question particles. Linguistic Inquiry 38. 139-166.

Cheng, Lisa L.-S. 1991. On the typology of wh-questions. Cambridge: Massachusetts Institute of Technology dissertation.

Cheng, Lisa L.-S. 1995. On dou-quantification. Journal of East Asian Linguistics (4). 197-234.

Cheng, Lisa L.-S. \& C.-T. James Huang. 1996. Two types of donkey sentences. Natural Language Semantics 4. 121-163.

Cheung, Candice C.-H. 2006. The syntax and semantics of bare conditionals in Chinese. In E. Puig-Waldmuller (ed.), Proceedings of Sinn und Bedeutung 11, 150-164. Barcelona: Universitat Pompeu Fabra.

Chierchia, Gennaro. 2000. Chinese conditionals and the theory of conditionals. Journal of East Asian Linguistics 9. 1-54.

Chomsky, Noam. 1965. Aspects of the theory of syntax. Cambridge, MA: MIT Press.

Chomsky, Noam. 2000. Minimalist inquiries: The framework. In R. E. A. Martin (ed.), Step by step: Essays on minimalist syntax in honor of Howard Lasnik, 89155. Cambridge, MA: MIT Press.

Chomsky, Noam. 2004. Beyond explanatory adequacy. In A. Belletti (ed.), Structures and beyond, 104-131. Oxford, NY: Oxford University Press.

Fukui, Naoki. 2015. A Note on weak vs. strong generation in human language. Studies in Chinese Linguistics 36(2). 59-68.

Giannakidou, Anastasia \& Lisa L.-S. Cheng. 2006. (In)definiteness, polarity, and the role of wh-morphology in free choice. Journal of Semantics 23. 135-183.

Hoji, Hajime. 1985. Logical form constraints and configurational structures in Japanese. Seattle: University of Washington dissertation.

Huang, C.-T. James. 1982. Logical relations in Chinese and the theory of grammar. Cambridge: Massachusetts Institute of Technology dissertation.

Huang, Shuan-Fan. 1981. On the scope phenomena of Chinese quantifiers. Journal of Chinese Linguistics 9. 226-243.

Huang, Yahui. 2010. On the form and meaning of Chinese bare conditionals: Not just whatever. Austin: The University of Texas dissertation.

Jiang, Li. 2012. Nominal arguments and language variation. Cambridge: Harvard University dissertation.

Kadmon, Nirit \& Fred Landman. 1993. Any. Linguistics and Philosophy 16. 353-422. 
Kuroda, Sige-Yuki 1965. Generative grammatical studies in the Japanese language. Cambridge: Massachusetts Institute of Technology dissertation.

Li, Y.-H. Audrey. 1992. Indefinite wh in Chinese . Journal of East Asian Linguistics 1. 125-155.

Lin, Jo-Wang. 1996. Polarity licensing and wh-phrase quantification in Chinese. Amherst: University of Massachusetts Dissertation.

Luo, Qiong-Peng \& Stephen Crain. 2011. Do Chinese wh-conditionals have relatives in other languages? Language and Linguistics 12. 753-798.

May, Robert. 1977. The grammar of quantification. Cambridge: Massachusetts Institute of Technology dissertation.

Fodor, Janet Dean \& Ivan Sag. 1982. Referential and quantificational indefinites. Linguistics and Philosophy 5. 355-398.

Reinhart, Tanya. 1997. Quantifier scope: How labor is divided between QR and choice functions. Linguistics and Philosophy 20. 335-397.

Tsai, Wei-Tien. 1994. On economizing the theory of A-bar dependencies. Cambridge: Massachusetts Institute of Technology dissertation.

Watanabe, Akira. 1992. Subjacency and S-structure movement of wh-in-situ. Journal of East Asian Linguistics 1. 255-291.

Address: $\quad$ Department of Linguistics, Boylston Hall 3rd floor, Cambridge, MA 02138 USA

Email: $\quad$ cyetsai@gmail.com

Received: March 2, 2015

Accepted: June 24, 2015 


\title{
論福井的評論
}

\author{
蔡承佑 \\ 哈佛大學
}

\section{提要}

本文從漢語量化結構的量詞範域與非疑問用法之疑問詞等兩個層面出發, 與福井 (2015) 對於弱性與強性生成的論點連結。本文認為這些現象對福井 (2015) 的看法 提供佐證: 以強性生成為基礎的研究有助我們對自然語言的理解, 並且不同的依存 關係必須由樹狀結構進行區分。

\section{關鍵詞}

強性生成, 依存關係, 漢語量化結構, 非疑問用法之疑問詞 